\title{
Numerical Solution of Dispersive Optical Solitons with Schrödinger-Hirota Equation by Improved Adomian Decomposition Method
}

\author{
H. O. Bakodah $\mathbb{D}^{1},{ }^{1}$ M. A. Banaja $\mathbb{D}^{1},{ }^{1}$ A. A. Alshaery, ${ }^{1}$ and A. A. Al Qarni ${ }^{2}{ }^{2}$ \\ ${ }^{1}$ Department of Mathematics, Faculty of Science, University of Jeddah, Jeddah, Saudi Arabia \\ ${ }^{2}$ Department of Mathematics, Faculty of Science, University of Bisha, Blqarn Campus, Saudi Arabia \\ Correspondence should be addressed to A. A. Al Qarni; alyaa14092009@hotmail.com
}

Received 14 February 2019; Accepted 21 April 2019; Published 27 May 2019

Academic Editor: Mariano Torrisi

Copyright (C) 2019 H. O. Bakodah et al. This is an open access article distributed under the Creative Commons Attribution License, which permits unrestricted use, distribution, and reproduction in any medium, provided the original work is properly cited.

In this paper, we present new numerical results for the dispersive optical soliton solutions of the nonlinear Schrödinger-Hirota equation. The spatio-temporal dispersion term is included, in addition to group velocity dispersion Kerr law of nonlinearity are studied. A general recursive numerical scheme for the equation is devised via the Improved Adomian Decomposition Method (IADM) and further sought for some analytical results for validation. The scheme is shown to be efficient and possessed high level of accuracy as demonstrated.

\section{Introduction}

Nonlinear Schrodinger equations (NLSE) play a significant role in the fiber optics, optical soliton, prorogation of pulses in metamaterials and network engineering applications among others $[1,2]$. Thus, different forms of NLSE exist and serve for a variety of purposes mostly in communication and networking engineering including, for example, the transcontinental and trans-oceanic data transfer requiring phase modulation [3] and beyond; see [4-16] for different mathematical studies on these equations. Furthermore, due to their immense application, many analytical methods and few numerical methods have been proposed in the past decades. Such methods include the Backlund transformation method [17], Hirota's direct method [18, 19], tanh-sech method [20, 21], extended tanh method [22, 23], sine-cosine method [24], and homogeneous balance method [25].

However, we will propose in this paper a numerical method for solving a class of NLSE called the nonlinear Schrodinger-Hirota equation. The method will heavily depend on the Improved Adomian Decomposition Method (IADM) [26-31]. The IADM is an efficient numerical method for functional and integral solutions based on the Adomian decomposition method [32]. Further, a recent analytical study on the nonlinear Schrodinger-Hirota equation will be sought for to validate the proposed scheme. This form of solution is being reported for the first time in this paper.

\section{Governing Equation}

The nonlinear Schrodinger equation used in modeling propagation of solitons through optical fibers with Third-Order Dispersion (TOD) is given by

$$
i u_{t}+\frac{1}{2} u_{x x}+|u|^{2} u=-i \lambda u_{x x x}
$$

where $u=u(x, t)$ is a complex-valued function of $x$ (space) and $t$ (time); $\lambda$ is the coefficient of TOD. The first term on the left hand side is the linear temporal evolution, the second term is the group velocity dispersion term, and the third term accounts for Kerr law nonlinearity. Also when the group velocity is low, the TOD is justified.

We now introduced the Lie symmetry concept to be able to study (1). With $q=q(x, t)$, let

$$
q=u-3 i \lambda\left[u_{x}+2 u \int_{-\infty}^{x}|u(\xi)|^{2} d \xi\right.
$$


which transforms (1) to

$$
i q_{t}+\frac{1}{2} q_{x x}+|q|^{2} q+i \lambda\left(q_{x x x}+6|q|^{2} q_{x}\right)=0
$$

In (3), higher order terms are neglected [11, 33, 34] with Kerr law nonlinearity that models transmission of dispersive optical solitons through nonlinear fibres. We express (3) with general coefficients as

$$
i q_{t}+a q_{x x}+c|q|^{2} q+i\left(\gamma q_{x x x}+\sigma|q|^{2} q_{x}\right)=0
$$

where physically $\sigma$ represents nonlinear dispersion. Further, (4) happens to be ill-posed due to the group velocity dispersion term. However, with the addition of the spatiotemporal dispersion (STD) term, (4) possesses a well-posedness [35, 36] given by

$$
i q_{t}+a q_{x x}+b q_{x t}+c|q|^{2} q+i\left(\gamma q_{x x x}+\sigma|q|^{2} q_{x}\right)=0
$$

where the coefficient $b$ represents STD. Finally, in presence of perturbation terms (5) becomes [37-39]

$$
\begin{aligned}
i q_{t} & +a q_{x x}+b q_{x t}+c|q|^{2} q+i\left(\gamma q_{x x x+} \sigma|q|^{2} q_{x}\right) \\
& =i \alpha q_{x}+i \lambda\left(|q|^{2} q\right)_{x}+i v\left(|q|^{2}\right)_{x} q .
\end{aligned}
$$

However, we consider an analytical 1-soliton solution of (6) as special case presented by Al Qarni et al. [40] for the numerical simulation sake in Section 4 given by

$$
q(x, t)=A \operatorname{sech}[B(x-v t)] e^{i\left(-k_{l} x+\omega_{l} t+\theta\right)},
$$

where $k$ is the frequencies of the solitons, $\omega$ is the wave number, $\theta$ is the phase velocity, and $A$ and $B$ are the amplitude and width $B$ given, respectively, by

$$
\begin{aligned}
& A=\sqrt{\frac{2\left(\omega+a k-\omega k b+a k^{2}+\gamma k^{3}\right)}{a-b v \omega-3 \gamma k},} \\
& B=\sqrt{\frac{2\left(\omega+a k-\omega k b+a k^{2}+\gamma k^{3}\right)}{c+\sigma k-\lambda k} .}
\end{aligned}
$$

The constraint conditions, for the existence of bright solitons from (7)-(9), are as follows:

$$
\begin{gathered}
(a-b v \omega-3 \gamma k)\left(2\left(\omega+a k-\omega k b+a k^{2}+\gamma k^{3}\right)\right)>0, \\
(c+\sigma k-\lambda k)\left(2\left(\omega+a k-\omega k b+a k^{2}+\gamma k^{3}\right)\right)>0 .
\end{gathered}
$$

\section{Numerical Method}

In [26-31], authors introduced the IADM to convert a special case of the complex-valued system into a real-valued system by splitting $q(x, t)$ as

$$
q(x, t)=u_{1}+i u_{2}
$$

where $\left(u_{k}, k=1,2\right)$ are real functions. By substituting equation (12) into (6) we obtain the following system:

$$
\begin{aligned}
& u_{1 t}+a u_{2 x x}+b u_{2 x t}+c\left(u_{1}^{2}+u_{2}^{2}\right) u_{2}+\gamma u_{1 x x x} \\
& +\sigma\left(u_{1}^{2}+u_{2}^{2}\right) u_{1 x}=\alpha u_{1 x}+\lambda\left(\left(u_{1}^{2}+u_{2}^{2}\right) u_{1}\right)_{x} \\
& \quad-v\left(u_{1 x}^{2}+u_{2 x}^{2}\right) u_{1}, \\
& u_{2 t}-a u_{1 x x}-b u_{1 x t}-c\left(u_{1}^{2}+u_{2}^{2}\right) u_{1}+\gamma u_{2 x x x} \\
& \quad+\sigma\left(u_{1}^{2}+u_{2}^{2}\right) u_{2 x}=\alpha u_{2 x}+\lambda\left(\left(u_{1}^{2}+u_{2}^{2}\right) u_{2}\right)_{x} \\
& \quad+v\left(u_{1 x}^{2}+u_{2 x}^{2}\right) u_{2},
\end{aligned}
$$

where

$$
\begin{aligned}
& u_{1}(x, 0)=[q(x, 0)]_{R}, \\
& u_{2}(x, 0)=[q(x, 0)]_{I} .
\end{aligned}
$$

The decomposition method [32] decomposes the solution into infinite sums of components defined by

$$
\begin{aligned}
& u_{1}(x, t)=\sum_{n=0}^{\infty} u_{1 n}(x, t), \\
& u_{2}(x, t)=\sum_{n=0}^{\infty} u_{2 n}(x, t),
\end{aligned}
$$

where the components $u_{1 n}, u_{2 n}, n \geq 0$ will be determined recursively. In an operator form with $L_{t}=\partial / \partial t$, (14) and (15) become

$$
\begin{aligned}
& L_{t}\left(u_{1}+b u_{2 x}\right)+a u_{2 x x}+c\left(u_{1}^{2}+u_{2}^{2}\right) u_{2}+\gamma u_{1 x x x} \\
& \quad+\sigma\left(u_{1}^{2}+u_{2}^{2}\right) u_{1 x}=\alpha u_{1 x}+\lambda\left(\left(u_{1}^{2}+u_{2}^{2}\right) u_{1}\right)_{x} \\
& \quad-v\left(u_{1 x}^{2}+u_{2 x}^{2}\right) u_{1}, \\
& L_{t}\left(u_{2}-b_{1} u_{1 x}\right)-a u_{1 x x}-c\left(u_{1}^{2}+u_{2}^{2}\right) u_{1}+\gamma u_{2 x x x} \\
& \quad+\sigma\left(u_{1}^{2}+u_{2}^{2}\right) u_{2 x}=\alpha u_{2 x}+\lambda\left(\left(u_{1}^{2}+u_{2}^{2}\right) u_{2}\right)_{x} \\
& \quad+v\left(u_{1 x}^{2}+u_{2 x}^{2}\right) u_{2} .
\end{aligned}
$$

Taking the inverse operator $L_{t}^{-1}$ to both sides of (18) and (19) gives

$$
\begin{aligned}
u_{1}(x, t)= & u_{1}(x, 0)-b\left(u_{2 x}(x, t)-u_{2 x}(x, 0)\right) \\
& -L_{t}^{-1} a u_{2 x x}-L_{t}^{-1} \gamma u_{1 x x x}+L_{t}^{-1} \alpha u_{1 x} \\
& +L_{t}^{-1} A_{1}, \\
u_{2}(x, t)= & u_{2}(x, 0)+b\left(u_{1 x}(x, t)-u_{1 x}(x, 0)\right) \\
& +L_{t}^{-1} a u_{1 x x}-L_{t}^{-1} \gamma u_{2 x x x}+L_{t}^{-1} \alpha u_{2 x} \\
& +L_{t}^{-1} A_{2} .
\end{aligned}
$$


Assuming that the nonlinear terms in (20) and (21) are represented by the series,

$$
\begin{aligned}
A_{1}= & -c\left(u_{1}^{2}+u_{2}^{2}\right) u_{2}-\sigma\left(u_{1}^{2}+u_{2}^{2}\right) u_{1 x} \\
& +\lambda\left(\left(u_{1}^{2}+u_{2}^{2}\right) u_{1}\right)_{x}+v\left(u_{1 x}^{2}+u_{2 x}^{2}\right) u_{1}, \\
A_{2}= & c\left(u_{1}^{2}+u_{2}^{2}\right) u_{1}-\sigma\left(u_{1}^{2}+u_{2}^{2}\right) u_{2 x} \\
& +\lambda\left(\left(u_{1}^{2}+u_{2}^{2}\right) u_{2}\right)_{x}+v\left(u_{1 x}^{2}+u_{2 x}^{2}\right) u_{2},
\end{aligned}
$$

$A_{1 n}, \ldots, A_{2 n}, \ldots$ are the so-called Adomian polynomials that can be constructed for all forms of nonlinearity according to specific algorithms set by Adomian [32]. Substituting the nonlinear terms into (22) and (23) and the solution from (16) and (17) into (20) and (21) gives

$$
\begin{aligned}
& \sum_{n=0}^{\infty} u_{1 n}(x, t) \\
& =u_{1}(x, 0)-b \sum_{n=0}^{\infty}\left(u_{2 n}(x, t)\right)_{x}+b\left(u_{2 n}(x, 0)\right)_{x} \\
& \quad-L_{t}^{-1} a \sum_{n=0}^{\infty}\left(u_{2 n}(x, t)\right)_{x x} \\
& \quad-L_{t}^{-1} \gamma \sum_{n=0}^{\infty}\left(u_{1 n}(x, t)\right)_{x x x}+L_{t}^{-1} \alpha \sum_{n=0}^{\infty}\left(u_{1 n}(x, t)\right)_{x} \\
& \quad+L_{t}^{-1} \sum_{n=0}^{\infty} A_{1 n}, \\
& \quad+L_{t}^{-1} \sum_{n=0}^{\infty} \gamma \sum_{n=0}^{\infty}\left(u_{2 n}(x, t)\right)_{x x x}+L_{t}^{-1} \alpha \sum_{n=0}^{\infty}\left(u_{2 n}(x, t)\right)_{x} \\
& \quad+L_{t}^{-1} a \sum_{n=0}^{\infty}\left(u_{1 n}(x, t)\right)_{x x} \\
& =u_{2}(x, 0)+b \sum_{n=0}^{\infty}\left(u_{1 n}(x, t)\right)_{x}-b\left(u_{1 n}(x, 0)\right)_{x}
\end{aligned}
$$

Following the decomposition analysis, the following recursive relations are introduced:

$$
\begin{aligned}
& u_{1,0}(x, t)=u_{1}(x, 0)+b\left(u_{2}(x, 0)\right)_{x}, \\
& u_{2,0}(x, t)=u_{2}(x, 0)-b\left(u_{1}(x, 0)\right)_{x},
\end{aligned}
$$

$$
\begin{aligned}
u_{1, k+1}(x, t)= & -b\left(u_{2, k}(x, t)\right)_{x}-L_{t}^{-1} a\left(u_{2, k}(x, t)\right)_{x x} \\
& -L_{t}^{-1} \gamma\left(u_{1, k}(x, t)\right)_{x x x} \\
& +L_{t}^{-1} \alpha\left(u_{1, k}(x, t)\right)_{x}+L_{t}^{-1} A_{1, m}, \\
u_{2, k+1}(x, t)= & b\left(u_{1, k}(x, t)\right)_{x}+L_{t}^{-1} a\left(u_{1, k}(x, t)\right)_{x x} \\
& +L_{t}^{-1} \gamma\left(u_{2 n}(x, t)\right)_{x x x} \\
& +L_{t}^{-1} \alpha\left(u_{2 n}(x, t)\right)_{x}+L_{t}^{-1} A_{2, m} .
\end{aligned}
$$

Thus, we determine $u_{1}$ and $u_{2}$ as follows:

$$
\begin{aligned}
& u_{1}=u_{1,0}+u_{1,1}+u_{1,2}+\cdots \\
& u_{2}=u_{2,0}+u_{2,1}+u_{2,2}+\cdots
\end{aligned}
$$

and the overall approximate solution for (6) is obtained by substituting the above into (12) coupled to (26)-(29) to get

$$
\begin{aligned}
q(x, t)= & u_{1,0}+u_{1,1}+u_{1,2}+\cdots \\
& +i\left(u_{2,0}+u_{2,1}+u_{2,2}+\cdots\right)
\end{aligned}
$$

\section{Numerical Results}

In this section, we consider three different cases for the Schrödinger-Hirota equation with spatiotemporal dispersion given in (6) to illustrate the application of the IADM scheme we presented in the above section. We also consider the bright soliton solution given in (7)-(11) for numerical simulation with the following fixed parameters: $\omega=1, k_{1}=k=0.1$, $\theta=0, c=1, a=0.5$. We also represent the graphs for absolute value for each of exact solution $q_{e}$ and approximate solution $q_{a}$.

Example 1. We consider Schrödinger-Hirota equation with spatiotemporal dispersion equation (6) with $b=0.0$ and the following three special cases.

Case 1. Let $\gamma=0.0$.

Case 2. Let $\gamma=0.6$.

Case 3. Let $\gamma=1.0$.

The results and the profiles of this example are presented in Table 1 and Figure 1.

Example 2. We consider Schrödinger-Hirota equation with spatiotemporal dispersion equation (6) with $b=0.1$ and the following three special cases.

Case 1. Let $\gamma=0.0$.

Case 2. Let $\gamma=0.6$.

Case 3. Let $\gamma=1.0$.

The result and the profiles of this example are presented in Table 2 and Figure 2. 

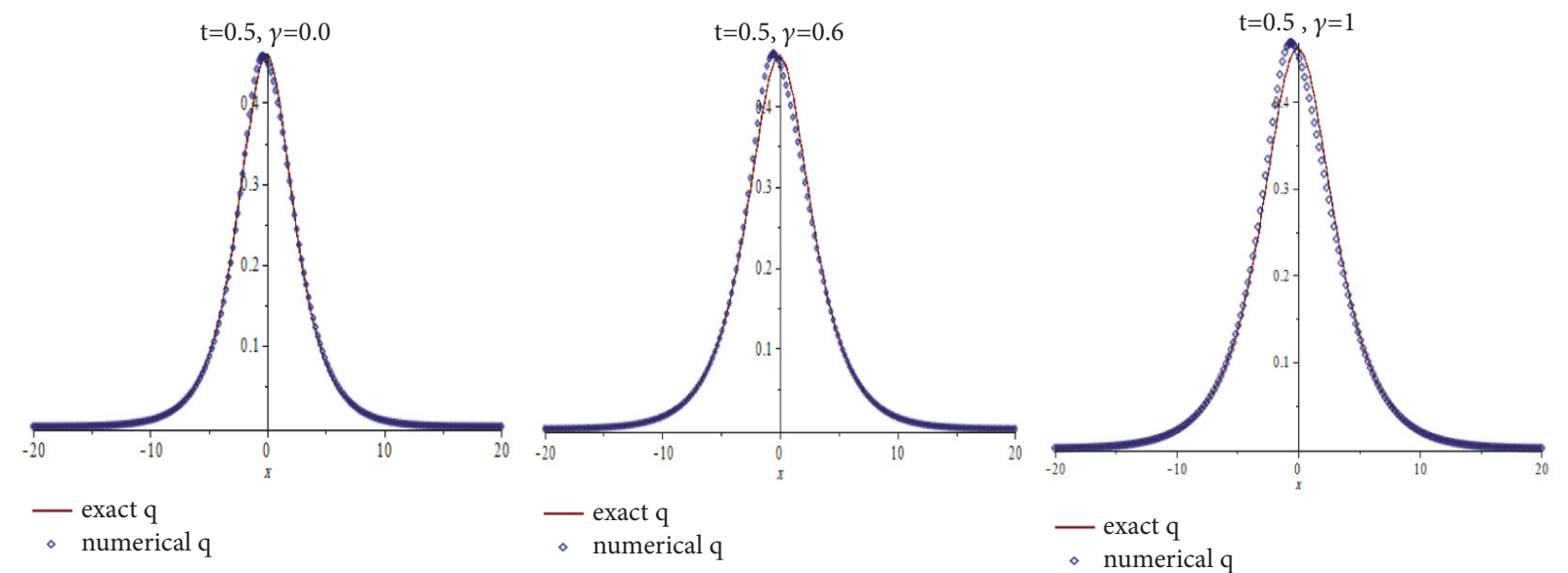

FIgURE 1: Comparison of the exact and approximate solution for Example 1 for $\mathbf{- 2 0} \leq \boldsymbol{x} \leq \mathbf{2 0}$.

TABLE 1: The absolute error for Example 1 when $x=20$.

\begin{tabular}{lccr}
\hline$t$ & $\gamma=0$ & $b=0$ & $\gamma=1$ \\
\hline 0.0 & 0.0 & $\gamma=0.6$ & 0.0 \\
0.1 & 0.000010261373 & 0.00003209069 & 0.00006378300 \\
0.2 & 0.000021764973 & 0.00006266170 & 0.00012599913 \\
0.3 & 0.000034488427 & 0.00009173715 & 0.00018667002 \\
0.4 & 0.000048407918 & 0.00011934200 & 0.00024581792 \\
0.5 & 0.000063498224 & 0.00014550173 & 0.00030346539 \\
\hline
\end{tabular}

TABLE 2: The absolute error for Example 2 when $x=20$.

\begin{tabular}{lccc}
\hline$t$ & & $b=0.1$ & $\gamma=1$ \\
\hline 0.0 & $5.47003 \times 10^{-7}$ & $\gamma=0.6$ & $8.7637 \times 10^{-7}$ \\
0.1 & 0.000013623790 & 0.00003154594 & 0.00006498593 \\
0.2 & 0.000028096531 & 0.00006216823 & 0.00012912151 \\
0.3 & 0.000043940472 & 0.00009113126 & 0.00019155154 \\
0.4 & 0.000061129371 & 0.00011845995 & 0.00025229764 \\
0.5 & 0.000079635465 & 0.00014417984 & 0.00031138194 \\
\hline
\end{tabular}
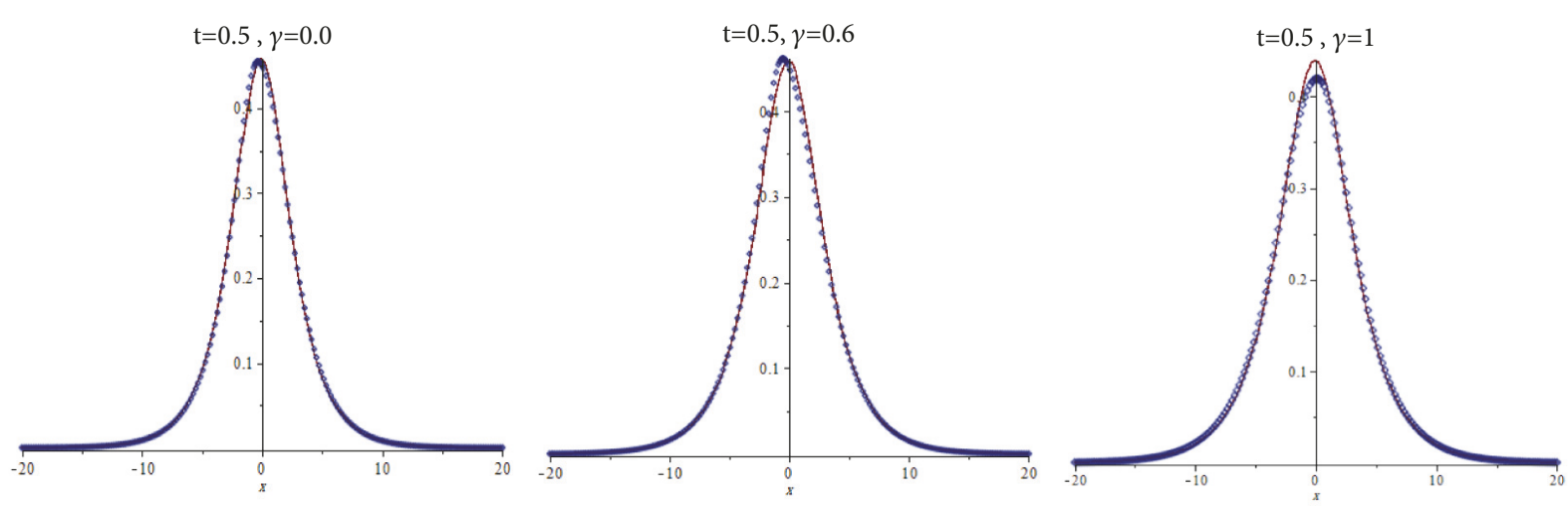

- exact q
numerical q

- exact q

- exact q

- numerical q

FIgURE 2: Comparison of the exact and approximate solution for Example 2 for $\mathbf{- 2 0} \leq \boldsymbol{x} \leq \mathbf{2 0}$. 
TABLE 3: The absolute error for Example 3 when $x=20$.

\begin{tabular}{lccc}
\hline$t$ & $\gamma=0$ & $b=0.6$ & $\gamma=1$ \\
\hline 0.0 & 0.00014373490 & $\gamma=0.6$ & 0.00019563219 \\
0.1 & 0.00014417980 & 0.00017576127 & 0.00009275551 \\
0.2 & 0.00014701256 & 0.00011583001 & 0.00000758921 \\
0.3 & 0.00015221500 & 0.00005817085 & 0.00010541473 \\
0.4 & 0.00015976708 & 0.00000366844 & 0.00020073458 \\
0.5 & 0.00016964674 & 0.00004859351 & 0.00029356299 \\
\hline
\end{tabular}

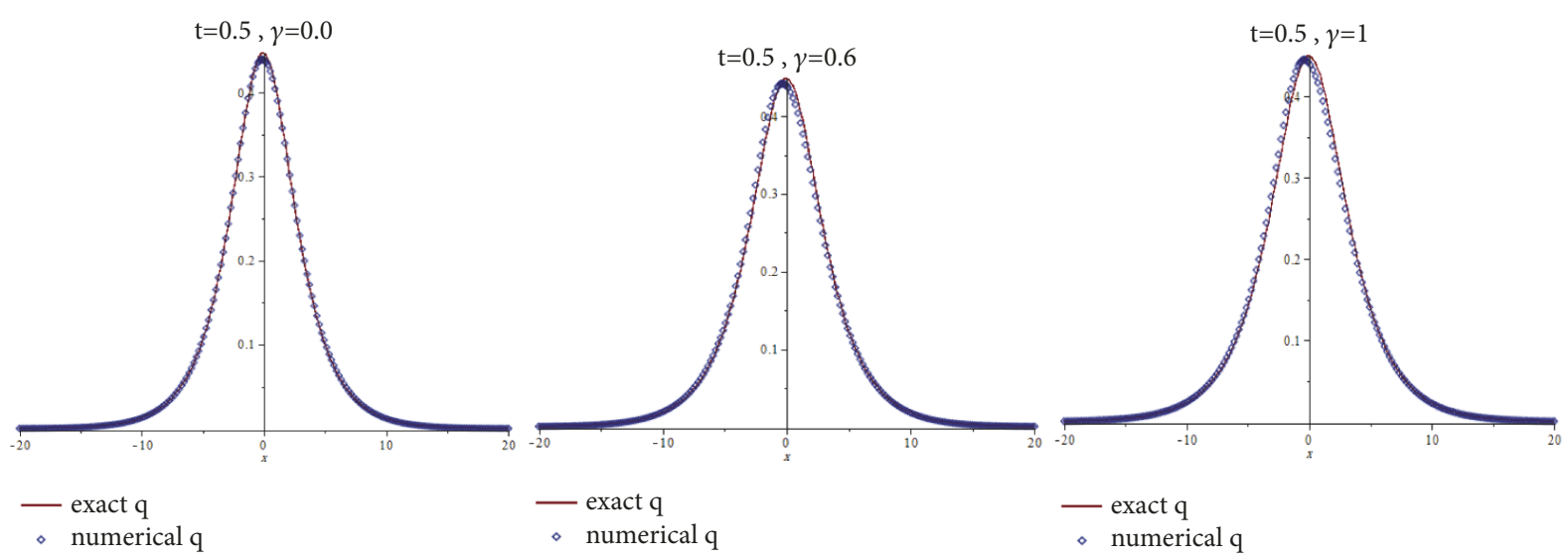

FIGURE 3: Comparison of the exact and approximate solution for Example 3 for $\mathbf{- 2 0} \leq \boldsymbol{x} \leq \mathbf{2 0}$.

Example 3. We consider Schrödinger-Hirota equation with spatiotemporal dispersion equation (6) with $b=0.6$ and the following three special cases.

Case 1. Let $\gamma=0.0$.

Case 2. Let $\gamma=0.6$.

Case 3. Let $\gamma=1.0$.

The result and the profiles of this example are presented in Table 3 and Figure 3.

\section{Conclusion}

In this work, an Improved Adomian Decomposition Method (IADM) has been proposed to solve the nonlinear Schrodinger-Hirota equation in presence of several Hamiltonian type perturbation terms. The obtained results possess high precision and converged to the exact solution with less computational efforts. It was noticed that a high accuracy of results is obtained when is the coefficient of 3OD $\gamma=0$ and within the range $0>\gamma, b<1$ ( $b$ is the coefficient of spatio-temporal dispersion term) as commented also in [40]. It is also clear from Figures 1-3 that the complete correspondence of the two solutions is indeed remarkable. Thus, the IADM is an efficient method for nonlinear Schrodinger equations since it shows a high level of accuracy with lesser computational efforts as compared to other numerical methods. This topic is still open for further researches for different values of parameters and other types of soliton solutions.

\section{Data Availability}

All the data used for the numerical simulations and comparison purpose have been reported in the tables included and visualized in the graphical illustrations and nothing is left.

\section{Conflicts of Interest}

The authors declare that they have no conflicts of interest.

\section{References}

[1] Y. Kodama and A. Hasegawa, "IV theoretical foundation of optical-soliton concept in fibers," Progress in Optics, vol. 30, pp. 205-259, 1992.

[2] V. E. Zakharov and S. Wabnitz, Optical Solitons: Theoretical Challenges and Industrial Perspectives, Springer, New York, NY, USA, 1999.

[3] M. J. Ablowitz and H. Segur, Solitons and the Inverse Scattering Transform, SIAM, Philadelphia, Pa, USA, 1981.

[4] I. Bernstein, E. Zerrad, Q. Zhou, A. Biswas, and N. Melikechi, "Dispersive optical solitons with Schrödinger-Hirota equation by traveling wave hypothesis," Optoelectronics and Advanced Materials - Rapid Communications, vol. 9, no. 5-6, pp. 792-797, 2015.

[5] G. P. Agarwal, Nonlinear Fiber Optics, Academic Press, 2001. 
[6] M. Younis, H. U. Rehman, and F. Tahir, "Optical Gaussons and dark solitons in directional couplers with spatiotemporal dispersion," Optical and Quantum Electronics, vol. 49, no. 12, 2018.

[7] A. Biswas, "Stochastic perturbation of optical solitons in Schrödinger-Hirota equation," Optics Communications, vol. 239, no. 4-6, pp. 461-466, 2004.

[8] R. K. Dowluru and P. R. Bhima, "Influences of third-order dispersion on linear birefringent optical soliton transmission systems," Journal of Optics (India), vol. 40, no. 3, pp. 132-142, 2011.

[9] P. D. Green and A. Biswas, "Bright and dark optical solitons with time-dependent coefficients in a non-Kerr law media," Communications in Nonlinear Science and Numerical Simulation, vol. 15, no. 12, pp. 3865-3873, 2010.

[10] A. J. Mohamad Jawad, M. D. Petkovic, and A. Biswas, "Soliton solutions of BURgers equations and perturbed BURgers equation," Applied Mathematics and Computation, vol. 216, no. 11, pp. 3370-3377, 2010.

[11] Y. Kodama and A. Hasegawa, "Nonlinear pulse propagation in a monomode dielectric guide," IEEE Journal of Quantum Electronics, vol. 23, no. 5, pp. 510-524, 1987.

[12] Y. Kodama, M. Romagnoli, S. Wabnitz, and M. Midrio, "Role of third-order dispersion on soliton instabilities and interactions in optical fibers," Optics Expresss, vol. 19, no. 3, pp. 165-167, 1994.

[13] G.-D. Lin, Y.-T. Gao, X.-L. Gai, and D.-X. Meng, "Extended double Wronskian solutions to the WHItham-Broer-Kaup equations in shallow water," Nonlinear Dynamics, vol. 64, no. 1-2, pp. 197-206, 2011.

[14] Q. Cao, T. Zhang, K. Djidjeli, G. . Price, and E. H. Twizell, "Soliton solutions of a class of generalized nonlinear Schrodinger equations," Applied Mathematics, vol. 12, no. 4, pp. 389-398, 1997.

[15] A. K. Sarma, "A comparative study of soliton switching in a twoand three-core coupler with TOD and IMD," Optik, vol. 120, no. 8, pp. 390-394, 2009.

[16] S. Tinggen, "Propagation characteristics of dark soliton study in optical fibers with slowly decreasing dispersion," Chinese Journal of Computational Physics, vol. 13, pp. 115-118, 1996.

[17] M. R. Miura, Backlund Transformation, Springer-Verlag, Berlin, Germany, 1978.

[18] R. Hirota, "Exact solution of the Korteweg-de-Vries equation for multiple Collisions of solitons," Physical Review Letters, vol. 27, no. 18, pp. 1192-1194, 1971.

[19] R. Hirota, The Direct Method in Soliton Theory, Cambridge University Press, Cambridge, UK, 2004.

[20] W. Malfliet and W. Hereman, "The tanh method. I. Exact solutions of nonlinear evolution and wave equations," Physica Scripta, vol. 54, no. 6, pp. 563-568, 1996.

[21] A. M. Wazwaz, "The tanh method for traveling wave solutions of nonlinear equations," Applied Mathematics and Computation, vol. 154, no. 3, pp. 713-723, 2004.

[22] S. A. El-Wakil and M. A. Abdou, "New exact travelling wave solutions using modified extended tanh-function method," Chaos, Solitons \& Fractals, vol. 31, no. 4, pp. 840-852, 2007.

[23] R. I. Nuruddeen, "Elzaki decomposition method and its applications in solving linear and nonlinear schrodinger equations," Sohag Journal of Mathematics, vol. 4, no. 2, pp. 31-35, 2017.

[24] A. M. Wazwaz, "A sine-cosine method for handling nonlinear wave equations," Mathematical and Computer Modelling, vol. 40, no. 5-6, pp. 499-508, 2004.
[25] M. Wang, Y. Zhou, and Z. Li, "Application of a homogeneous balance method to exact solutions of nonlinear equations in mathematical physics," Physics Letters A, vol. 216, no. 1-5, pp. 67-75, 1996.

[26] H. O. Bakodah, M. A. Banaja, A. A. Alqarni et al., "Optical solitons in birefringent fibers with adomian decomposition method," Journal of Computational and Theoretical Nanoscience, vol. 12, no. 12, pp. 5846-5853, 2015.

[27] A. A. Qarni, M. A. Banaja, H. O. Bakodah, M. Mirzazadeh, and A. Biswas, "Optical solitons with coupled nonlinear schrodinger's equation in birefringent nano-fibers by adomian decomposition method," Journal of Computational and Theoretical Nanoscience, vol. 13, no. 8, pp. 5493-5498, 2016.

[28] A. A. Al Qarni, M. A. Banaja, H. O. Bakodah, A. A. Alshaery, F. B. Majid, and A. Biswas, "Optical solitons in birefringent fibers: A numerical study," Journal of Computational and Theoretical Nanoscience, vol. 13, no. 11, pp. 9001-9013, 2016.

[29] A. Al-Shareef, A. A. Al Qarni, S. Al-Mohalbadi, and H. O. Bakodah, "Soliton solutions and numerical treatment of the nonlinear schrodinger's equation using modified adomian decomposition method," Journal of Applied Mathematics and Physics, vol. 04, no. 12, pp. 2215-2232, 2016.

[30] H. O. Bakodah, A. A. Al Qarni, M. A. Banaja, Q. Zhou, S. P. Moshokoa, and A. Biswas, "Bright and dark thirring optical solitons with improved adomian decomposition method," Optik, vol. 130, pp. 1115-1123, 2017.

[31] M. A. Banaja, A. A. Al Qarni, H. O. Bakodah, Q. Zhou, S. P. Moshokoa, and A. Biswas, "The investigate of optical solitons in cascaded system by improved adomian decomposition scheme," Optik, vol. 130, pp. 1107-1114, 2017.

[32] G. Adomian, "Solution of physical problems by decomposition," Computers \& Mathematics with Applications, vol. 27, no. 9-10, pp. 145-154, 1994.

[33] A. Hasegawa and Y. Kodama, Solitons in Optical Communications, Oxford University Press, Oxford, UK, 1995.

[34] S. Wabnitz, Y. Kodama, and A. B. Aceves, "Control of optical soliton interactions," Optical Fiber Technology, vol. 1, no. 3, pp. 187-217, 1995.

[35] X. Geng and Y. Lv, "Darboux transformation for an integrable generalization of the nonlinear Schrödinger equation," Nonlinear Dynamics, vol. 69, no. 4, pp. 1621-1630, 2012.

[36] S. Kumar, K. Singh, and R. K. Gupta, "Coupled Higgs field equation and Hamiltonian amplitude equation: lie classical approach and (G'/G)-expansion method," Pramana, vol. 79, no. 1, pp. 41-60, 2012.

[37] M. Inc, A. I. Aliyu, A. Yusuf, and D. Baleanu, "Dispersive optical solitons and modulation instability analysis of SchrödingerHirota equation with spatio-temporal dispersion and Kerr law nonlinearity," Superlattices and Microstructures, vol. 113, pp. 319$327,2018$.

[38] Y. Yildirim, "Optical solitons to SchrödingerHirota equation in DWDM system with trial equation integration architecture," Optik, vol. 18, pp. 275-281, 2019.

[39] A. Biswas, Y. Yildirim, E. Yasar et al., "Dispersive optical solitons with Schrödinger-Hirota model by trial equation method," Optik - International Journal for Light and Electron Optics, vol. 162, pp. 35-41, 2018.

[40] A. A. Al Qarni, M. A. Banaja, and H. O. Bakodah, "Numerical analyses optical solitons in dual core couplers with kerr law nonlinearity," Applied Mathematics, vol. 06, no. 12, pp. 19571967, 2015. 


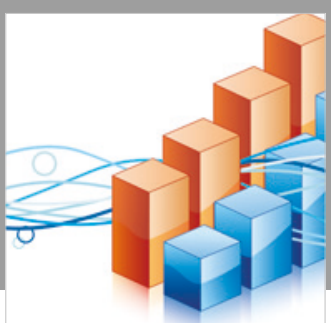

Advances in

Operations Research

\section{-n-m}
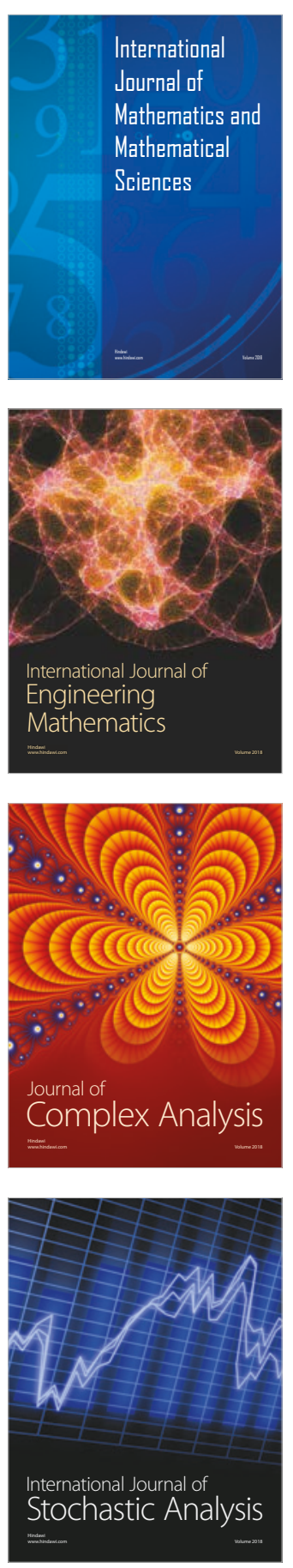
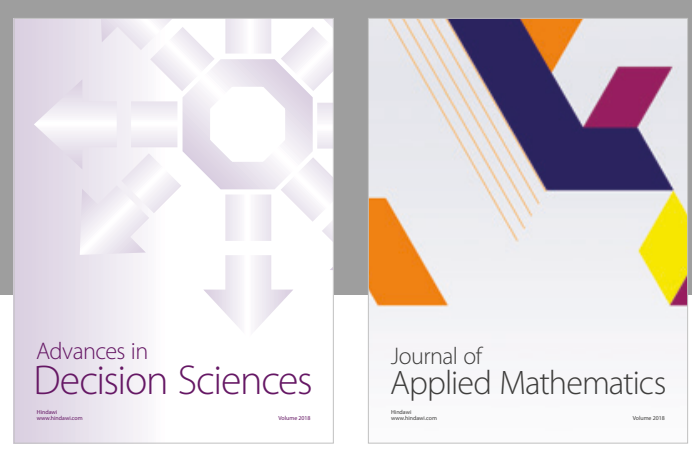

Journal of

Applied Mathematics
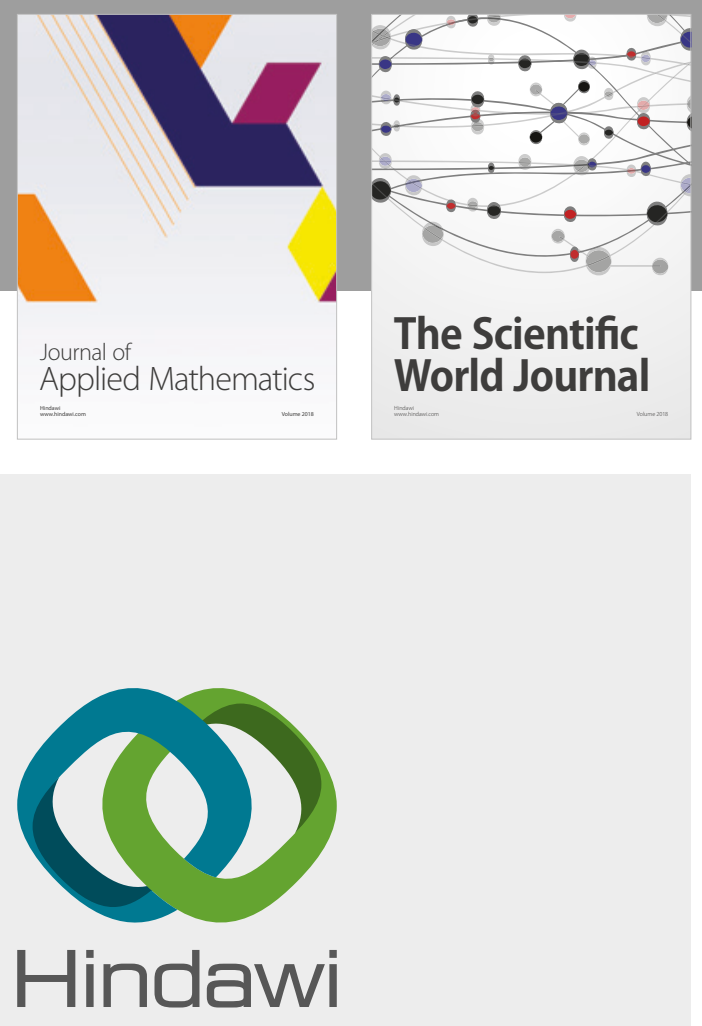

Submit your manuscripts at

www.hindawi.com

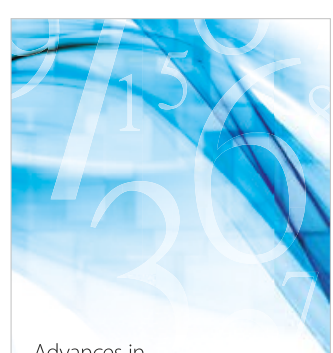

Advances in
Numerical Analysis
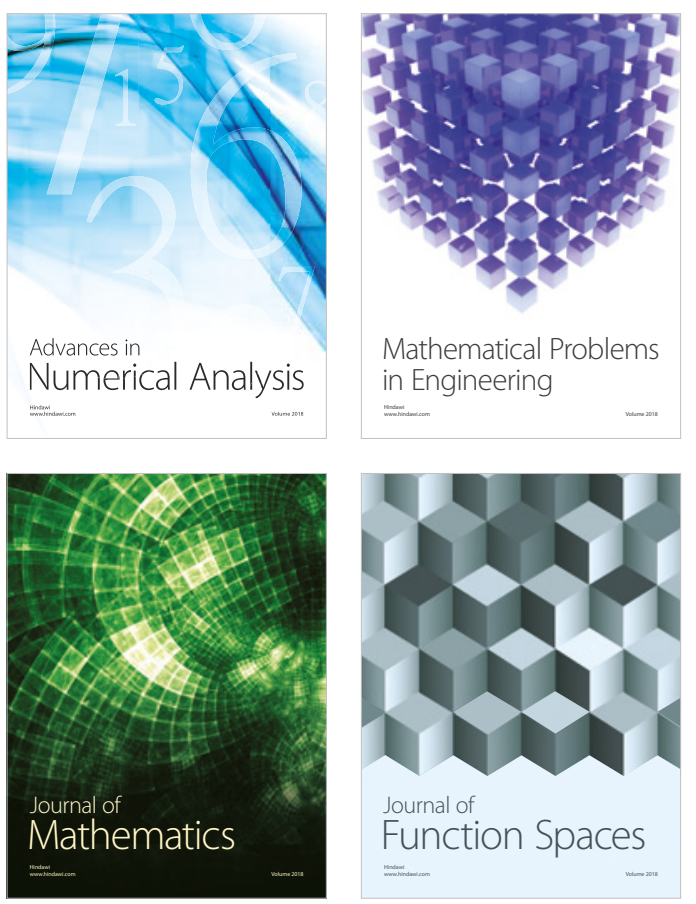

Mathematical Problems in Engineering

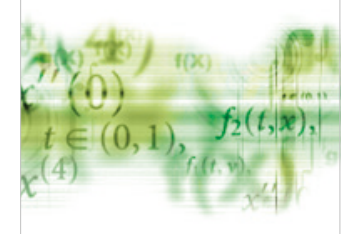

International Journal of

Differential Equations

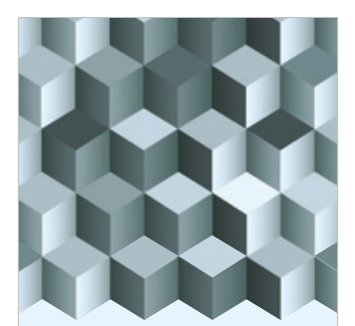

Journal of

Function Spaces

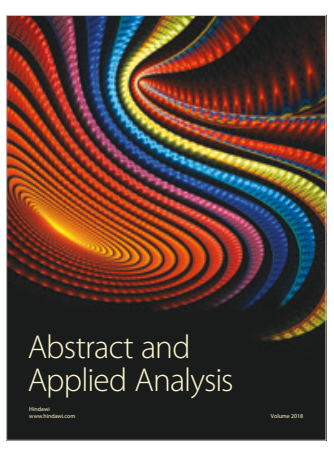

The Scientific

World Journal

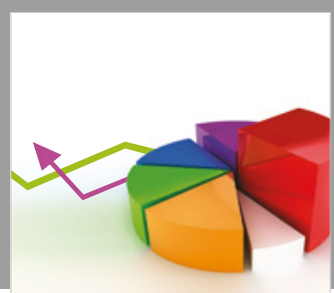

Journal of

Probability and Statistics
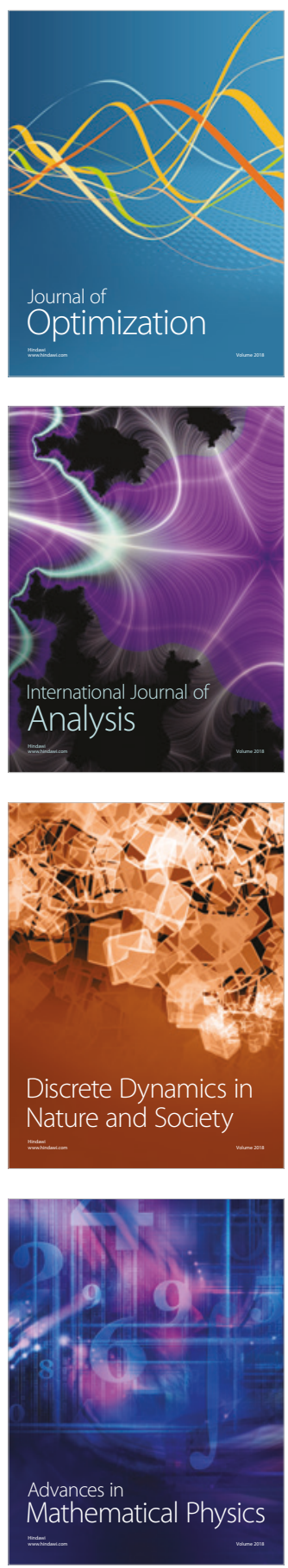